\title{
Improving Measures of Sexual and Gender Identity in English and Spanish to Identify LGBT Older Adults in Surveys
}

\author{
Stuart Michaels, $\mathrm{PhD},{ }^{1}$ Carolina Milesi, $\mathrm{PhD}^{2}$ Michael Stern, $\mathrm{PhD}^{3}$, Melissa Heim Viox, MPH, \\ Heather Morrison, MA, Paul Guerino, MS, ${ }^{5}$ Christina N. Dragon, $\mathrm{MSPH}^{5}$, and Samuel C. Haffer, $\mathrm{PhD}^{5}$
}

\begin{abstract}
Purpose: The goal of this research is to advance the study of health disparities faced by older sexual and gender minorities by assessing comprehension of and improving measures of sexual and gender identity in surveys.

Methods: Cognitive interviews were conducted by expert interviewers with 48 non-lesbian, gay, bisexual, and transgender (non-LGBT) and 9 LGBT older English and Spanish speakers.

Results: All respondents were able to answer questions about their sex assigned at birth and current gender identity successfully despite some cisgender respondents' lack of clear understanding of the transgender response option. On the contrary, while the vast majority of English speakers could answer the question about their sexual identity successfully, almost $60 \%$ of the non-LGBT Spanish speakers did not select the "heterosexual, that is, not gay (or lesbian)" response category. Qualitative probing of their response process pointed mainly to difficulties understanding the term "heterosexual," leading to their choosing "something else" or saying that they didn't know how to answer. A second round of testing of alternative response categories for the sexual identity question with Spanish speakers found a marked improvement when offered "not gay (or lesbian), that is, heterosexual" instead of beginning with the term "heterosexual."

Conclusion: This research adds to our understanding of gender and sexual identity questions appropriate for population surveys with older adults. Inclusion of these measures in surveys is a crucial step in advancing insights into the needs of and disparities faced by LGBT older adults.
\end{abstract}

Keywords: gender identity, LGBT aging, sexual identity, survey measurement

\section{Introduction}

O LDER LGBT adults experience disparities in many areas, including access to healthcare, social isolation, access to caregiving, financial stability, housing, discrimination, and minority stress, as well physical and mental health outcomes according to recent articles. ${ }^{1-3}$ To address the social and health disparities faced by older LGBT adults, we need more and better data, especially from population studies. There is an increasing number of large nationally representative surveys that include measures of sexual orientation (e.g., National Health Interview Survey [NHIS], National Health and Nutrition Examination Survey [NHANES], and the General Social Survey [GSS]), and important recent work has looked at adult LGB health disparities using data from the NHIS. ${ }^{4-6}$ However, Choi and Meyer were only able to find two studies focused specifically on disparities faced by older LGBT adults drawing on representative population samples, and these were based on state-level data not national surveys. ${ }^{1}$ To date, there are no national surveys that include gender identity measures that would allow one to identify transgender older adults.

One of the crucial steps to advance research on the specific needs and disparities of older LGBT adults is high-quality survey measures of sexual and gender identity that work well among older adults. To this end, we report on research from two waves of cognitive interviews in English and Spanish with LGBT and non-LGBT Medicare beneficiaries to assess their comprehension of and ability to answer recommended, best practice survey questions on sexual orientation and gender identity. ${ }^{7,8}$ This research was undertaken by researchers at NORC at the University of Chicago for the Centers for

\footnotetext{
${ }^{1}$ Academic Research Centers, NORC at the University of Chicago, Chicago, Illinois.

${ }^{2}$ Education and Child Development Department, NORC at the University of Chicago, Chicago, Illinois.

${ }^{3}$ Center for Excellence in Survey Research, NORC at the University of Chicago, Chicago, Illinois.

${ }^{4}$ Health Sciences, NORC at the University of Chicago, Chicago, Illinois.

${ }^{5}$ Office of Minority Health, Centers for Medicare \& Medicaid Services, Baltimore, Maryland.
} 
Medicare \& Medicaid Services (CMS) to find and test measures for possible inclusion in the Medicare Current Beneficiary Survey (MCBS).

The goal of this research project was to advance the study of health disparities experienced by older sexual and gender minorities by investigating comprehension and response problems of Medicare eligible adults to sexual and gender identity questions in surveys. Cognitive interviews were used to test the performance of questions and generate qualitative data to improve survey measures. ${ }^{9,10}$ Interviews were conducted with a larger number of non-LGBT adults and a smaller number of LGBT adults as prior research has found that, in general, LGBT respondents do not have trouble understanding and answering questions about their sexual and gender identity, whereas a non-negligible segment of the non-LGBT population has comprehension problems with such questions. ${ }^{11,12}$ In addition, there were indications in this extensive research to develop the sexual identity question for the NHIS that non-English speakers, especially Spanish speakers, have cultural and language comprehension problems with the sexual identity question response categories. While "gay" is an English word that is becoming more widespread among Spanish speakers, in general, it may be unfamiliar to older Spanish speakers. Therefore, a second major goal was to test both sexual and gender identity questions with older Spanish as well as English speakers.

Although the number of surveys that include measures allowing one to identify lesbian, gay, bisexual, or transgender respondents is still relatively low, the findings from these surveys, the cognitive testing of the measures, and pretests have provided some evidence that the Spanish translation of these items is not always understood well. Extensive testing of the sexual identity question found that the rates of missing data for the Spanish version of the question were consistently higher than in the English version. Miller and Ryan argued that one of the reasons for these findings is the lack of a Spanish equivalent for the English term "straight" as well as the term "gay." 11 Spanish speakers represent the largest nonEnglish speaking group in the United States.

\section{Methods}

Based on an earlier review of the literature and existing surveys ${ }^{13}$ as well as expert panel reviews and recommendations on measures of sexual orientation and gender identity in surveys, ${ }^{7,8}$ three questions were selected for testing: a single question on sexual identity from the NHIS ${ }^{4,12}$ and two questions to assess gender identity following the recommendation of an expert panel. ${ }^{8}$ The exact English wording of the questions appears in Table 1.

The Spanish translation of these questions can be found in Table 2. The translation into Spanish of the sexual identity question does pose one challenge. There is no equivalent in Spanish to "straight." Therefore, the Spanish translation uses "heterosexual," which is exactly the same word in Spanish as in English. We used the Spanish translation of the two questions to determine sex assigned at birth and current gender identity that had been developed and used by the California Health Interview Survey. ${ }^{14}$ This translation uses the Spanish words for man (hombre) and woman (mujer) instead of male and female used in English.
Table 1. Sexual Identity and Gender IDENTITY QUESTIONS, ENGLISH

Which of the following best represents how you think about yourself? ${ }^{\mathrm{a}}$

SHOW CARD

(01) (Lesbian or) gay

(02) Straight, that is, not (lesbian or) gay

(03) Bisexual

(04) Something else

(05) I don't know how to answer

What sex were you assigned at birth, on your original birth certificate? $^{\mathrm{b}}$

(01) FEMALE

(02) MALE

How do you describe yourself? ${ }^{\mathrm{b}}$ (select one)

SHOW CARD

(01) Female

(02) Male

(03) Transgender

(04) Do not identify as female, male, or transgender

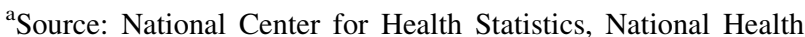
Interview Survey, 2013. Note that "Lesbian or" which appears here in parentheses, is added in responses presented to female respondents.

${ }^{b}$ Source: The GenIUSS Group. ${ }^{8}$

Before in-person interviews, as part of the telephone screening process, potential participants were asked the following two questions: Are you male or female? Do you, personally, identify as lesbian, gay, bisexual, or transgender? The latter question had a yes/no response option. The responses to

Table 2. Spanish Versions of Sexual Identity AND GENDER IDENTITY QUESTIONS

Sexual identity question

¿Cuál de las siguientes mejor representa su manera de pensar en sí mismo?

\begin{tabular}{lc}
\hline $\begin{array}{l}\text { [Response options } \\
\text { for male Rs]: }\end{array}$ & $\begin{array}{c}\text { [Response options } \\
\text { for female Rs]: }\end{array}$ \\
\hline Gay & Lesbiana o gay \\
Heterosexual, o sea, no gay & Heterosexual, o sea, \\
& no gay o lesbiana \\
Bisexual & Bisexual \\
Otra cosa & Otra cosa \\
No sé la respuesta & No sé la respuesta \\
\hline
\end{tabular}

Gender identity questions

¿Qué sexo le asignaron al nacer, en su acta de nacimiento original?

Hombre

Mujer

¿Se describe a sí mismo(a) como hombre, mujer o transgénero?

Hombre

Mujer

Transgénero

No me identifico como mujer, hombre ni transgénero 
Table 3. Number of Respondents by Lesbian, Gay, Bisexual, and Transgender Identity, Sex, Age Group, Education, and Language in Which the Interview Was Conducted

\begin{tabular}{|c|c|c|c|c|c|c|c|c|c|}
\hline \multirow{3}{*}{$\begin{array}{l}\text { Language and LGBT identity } \\
\text { reported in screener }\end{array}$} & \multirow{2}{*}{\multicolumn{2}{|c|}{ Sex }} & \multicolumn{2}{|c|}{ Education } & \multicolumn{4}{|c|}{ Age } & \multirow[b]{3}{*}{ Total } \\
\hline & & & \multirow{2}{*}{$\begin{array}{l}\text { Less than } \\
\text { high school }\end{array}$} & \multirow{2}{*}{$\begin{array}{l}\text { High school } \\
\text { and above }\end{array}$} & \multirow{2}{*}{$\begin{array}{l}\text { Less than } \\
59 \text { years }\end{array}$} & \multirow{2}{*}{$\begin{array}{l}60-69 \\
\text { years }\end{array}$} & \multirow{2}{*}{$\begin{array}{l}70-79 \\
\text { years }\end{array}$} & \multirow{2}{*}{$\begin{array}{l}80-89 \\
\text { years }\end{array}$} & \\
\hline & Male & Female & & & & & & & \\
\hline \multicolumn{10}{|l|}{ English speaking } \\
\hline Non-LGBT & 5 & 10 & 1 & 14 & 3 & 4 & 5 & 3 & 15 \\
\hline LGBT & 4 & 1 & 0 & 5 & 2 & 0 & 2 & 1 & 5 \\
\hline \multicolumn{10}{|l|}{ Spanish speaking } \\
\hline Non-LGBT & 11 & 22 & 26 & 7 & 3 & 15 & 11 & 4 & 33 \\
\hline LGBT & 2 & 2 & 0 & 4 & 2 & 1 & 1 & 0 & 4 \\
\hline
\end{tabular}

LGBT identity, sex, education, and age as reported in screener.

LGBT, lesbian, gay, bisexual, and transgender.

these questions were used to classify respondents' sex and LGBT identity in the analysis of the cognitive interviews.

An initial round of cognitive interviews was conducted with 20 English- and 37 Spanish-speaking Medicare eligible respondents (average age 67 years). The sample included 22 males and 35 females; 9 LGBT and 48 non-LGBT adults (based on their responses to the screener). The 48 non-LGBT persons are presumed to be cisgender* heterosexuals in the analysis that follows, based on their negative response to the screener question about whether they identified as LGBT. ${ }^{\dagger}$ Table 3 displays the number of participants by sex and LGBT identity as reported in the screener, as well as respondents' education, age, and the language in which the interview was conducted. English-speaking respondents represented a range of racial backgrounds-White, Black, Asian, and American Indian. The Spanish-speaking respondents included a variety of nationalities-Mexican, Puerto Rican, Honduran, Salvadorian, Nicaraguan, Panamanian, Cuban, and Peruvian. All but one English respondent reported having an education level of high school or more. Spanish-speaking respondents had lower levels of education than English-speaking respondents: $70 \%(n=26)$ of Spanish-speaking respondents had not completed high school and 30\% $(n=11)$ had an education level of high school or more. Of the LGBT adults, six were male and three were female; five were English speakers and four were Spanish speakers; and eight identified as lesbian, gay, or bisexual and one as "a transsexual woman attracted to men."

*Cisgender is an adjective that originated in the 1990s as a neutral term to contrast with transgender. It refers to persons "whose sense of personal identity and gender corresponds with their birth sex"(English Oxford Living Dictionaries (US). Cisgender. Available at https:// en.oxforddictionaries.com/definition/us/cisgender Accessed October 1, 2016).

Since the two questions on the initial telephone screener for participants are less precise than the questions on sex at birth, current gender identity, and sexual orientation/identity that were tested in the cognitive interviews, we only learned potential respondents' current sex/gender and whether they identify as lesbian, gay, bisexual or transgender. This unfortunate conflation of gender identity and sexual orientation forced us to presume that respondents were cisgender unless they explicitly told us otherwise. One respondent did tell us that she was transgender at the time of recruitment but we could only assume that all other respondents were cisgender including lesbian, gay, and bisexual respondents.
The initial set of cognitive interviews took place between August 2015 and January 2016 in Chicago, Atlanta, and Washington, D.C. Recruitment targeted Medicare beneficiaries and oversampled Spanish speakers of diverse national origins to account for variations in the understandings of sexual identity and gender identity based on cultural and demographic differences. The cognitive interview protocol and all materials, including the recruitment script, eligibility screener questionnaire, and participant written consent form, were approved by the NORC Institutional Review Board. All interviews were recorded and interviewers used these recordings when preparing their notes, transcribing key sections of the interview, and translating from Spanish to English. Based on the screener questions about sex and LGBT identity, we were able to compare screener results with responses to the questionnaire items on sexual identity, sex assigned at birth, and gender identity, shown in Tables 1 and 2.

\section{Results}

We first report results from testing of the sexual identity items among English and Spanish speakers, and then report results from testing the gender identity items for English and Spanish speakers. We present the main themes that arose during cognitive testing of sexual identity and gender identity items for each language group. For each theme, representative examples of interviewer queries and respondents' responses from the transcripts are presented.

\section{Sexual identity}

Table 4 presents a comparison of respondents' responses to the initial screener and their responses to the sexual identity question in the cognitive interviews for English and Spanish speakers. The vast majority $(87 \%)$ of the non-LGBT English speakers identified themselves as straight, which corresponded to their response on the screener. Two did not know how to answer the question. On the contrary, the majority $(58 \%)$ of the nonLGBT Spanish speakers did not report that they were heterosexual. One chose "bisexual" and the rest selected "something else" or "don't know how to answer." A number of different themes emerged from their responses to the probes about how they arrived at their responses in the cognitive interviews.

Conflation of sexual identity and gender identity. Two English speakers and the majority of Spanish speakers did not 
Table 4. Comparison of Responses to the Lesbian, Gay, Bisexual, and Transgender Identity

Question in the Screener with Responses to the Sexual IDEntity Question in Cognitive InTERVIEWs Among ENGLISH- AND SPANISH-SPEAKING RESPONDENTS

\begin{tabular}{|c|c|c|c|c|c|c|}
\hline \multirow[b]{2}{*}{$\begin{array}{l}\text { Reported at screener: Do you, } \\
\text { personally, identify as lesbian, } \\
\text { gay, bisexual, or transgender? }\end{array}$} & \multicolumn{6}{|c|}{$\begin{array}{c}\text { Reported at cognitive interview: Which of the following best represents } \\
\text { how you think about yourself? }\end{array}$} \\
\hline & $\begin{array}{l}\text { Lesbian } \\
\text { or gay }\end{array}$ & $\begin{array}{c}\text { Straight/ } \\
\text { heterosexual }\end{array}$ & Bisexual & $\begin{array}{l}\text { Something } \\
\text { else }\end{array}$ & $\begin{array}{l}\text { Don't know } \\
\text { how to answer }\end{array}$ & $\begin{array}{l}\text { Something else } \\
\text { and don't know } \\
\text { how to answer }\end{array}$ \\
\hline \multicolumn{7}{|l|}{ English-speaking respondents } \\
\hline Yes & 5 & 0 & 0 & 0 & 0 & 0 \\
\hline No & 0 & 13 & 0 & 0 & 2 & 0 \\
\hline \multicolumn{7}{|l|}{ Spanish-speaking respondents } \\
\hline Yes & 2 & 0 & 1 & 1 & 0 & 0 \\
\hline No & 0 & 14 & 1 & 6 & 10 & 2 \\
\hline
\end{tabular}

clearly distinguish sexual identity from gender identity. They explained their answers to the question about their sexual identity by indicating that they were "male" or "female," a "real man or real woman," or "100 percent male or female."

- [R121, English, 81 years] Male, Not-LGBT/Male, Straight": “I'm 100 percent male or man. I'm a man. I know who I am. 100 percent.",

- [R129, Spanish, 73 years] Female, Not-LGBT/Female, Don't know: "I have not been this, I have not been that, that question I wouldn't know how to answer. I identify as a woman... who hasn't been any of this [...] I consider myself a woman ...100 percent a woman."

Discomfort with question. Some English respondents and several Spanish respondents expressed discomfort with the sexual identity question and inquired about why this information was being collected. Discomfort was related to public disclosure of sexual identity; difficulty discussing any sexrelated issues; moral concerns about nonheteronormative sexual identity; or answering the question without fully understanding the terms.

- [R150, English, 78 years] Female, Not-LGBT/Female, Don't know: When the interviewer asked "What did you think about when I asked that question?" the respondent said "Very unusual...not really unusual in this day and age, but still to me, it's unusual to be answering questions like this. I'm 78 years old. I've been married for 39 years to the same man."

- [R125, Spanish, 71 years] Female, Not-LGBT/Female, Don't know: "I thought you were asking me if I was a lesbian or if I was a man. I felt a bit uncomfortable, since I am a woman [...] The only question I have is why you are asking me all these questions if I am telling you I am $100 \%$ woman.",

"Normal" sexual identity. Heterosexual participants identified their sexual identity as "normal." Spanish-speaking

\footnotetext{
The first two terms after the square parentheses indicate R's classification of their sex and LGBT identity during the screener. The last two terms indicate R's classification of their current gender identity and sexual identity during the cognitive interview.
}

respondents also referred to themselves as "regular," "correct," "complete," a "very good person," or indicated that they do not have a mental illness.

- [R118, English, 78 years] Female, Not-LGBT/Female, Straight: When asked what she was thinking about when answering, she said "I'm normal and straight was normal, others were not.'

- [R151, Spanish, 75 years] Female, Not-LGBT/Female, Something else: When the interviewer asked "what else would best represent how you think about yourself?" the respondent said "A normal woman....I am married, I have my family, my children."

Limited response options. Two LGBT Spanish-speaking respondents questioned the lack of exhaustive response options. The transgender respondent who identified as a "transsexual woman attracted to men" thought that none of the response categories applied to her and she selected "something else." A gay respondent recommended adding the response "questioning" for individuals who are uncertain of their sexual identity.

Comprehension and consistency of responses to the sexual identity question. Follow-up discussion in the cognitive interviews indicated that the vast majority of Englishspeaking respondents were able to understand the sexual identity question and response categories. As shown in Table 4, all but two English respondents provided consistent responses between the screener and cognitive interview when the actual wording of the sexual identity item was tested. On the contrary, most Spanish-speaking respondents exhibited comprehension problems, especially women and those with lower levels of education. Most of the nonLGBT Spanish-speaking respondents were uncertain of the meaning of "heterosexual," which prevented them from selecting the appropriate response category. Most respondents described a process in which they decided what to answer based on the elimination of categories that they did not know or that did not apply to them. Therefore, many Spanish speakers who stated that they were not LGBT during the screening process, selected a category that was "not gay," "not heterosexual," and "not bisexual" when reviewing the response categories for the sexual identity question, as they thought that none of these categories described them. 
As Table 4 shows, $58 \%$ of Spanish respondents did not select "heterosexual" during the interview even though they had stated that they were not LGBT in the screener. Among these respondents, all but one answered "I don't know how to answer" or "Something else."

- [R125, Spanish, 71 years] Female, Not-LGBT/Female, Don't know: "I don't identify with any of those categories...I hear now on TV what it means to be a lesbian, heterosexual, all those things.",

- [R134, Spanish, 70 years] Male, Not-LGBT/Male, Don't know: When asked "What did you think about when I asked that question?" he said "I thought I was something else. I am neither gay, nor heterosexual, nor bisexual... I am none of these [categories]." He defined heterosexual as "don't know... somebody who likes other... bad habits! ["mala maña"']."

- [R135, Spanish, 68 years] Male, Not-LGBT/Male, Something else: When asked "Did you have any trouble deciding on that answer?" the respondent said "no, but the question was a bit confusing... I don't know what I could answer, since I am neither gay, heterosexual, nor bisexual. So, I started thinking. I know what the question is about, so I decided to answer 'something else'.'

- [R154, Spanish, 66 years] Female, Not-LGBT/Female, Don't know: When the interviewer first asked this question, the respondent carefully read all of the response categories and asked 'What does 'something else' mean?" Asked "If you had to choose one option, what would you choose?" she said: "Well, heterosexual. No. I am not gay. Lesbian even less so! What does the word bisexual mean? Hmm. Both sides? No, no, no, no. I don't know how to answer. I'd select that.'

\section{Gender identity}

Sex assigned at birth and current gender identity. All English- and Spanish-speaking respondents understood these questions in the cognitive interview and answered them in a way that was consistent with the responses that they provided to the two questions in the screener. This includes the transgender Spanish respondent who said she was assigned male at birth and selected woman in response to her current gender identity. The current gender identity question presented challenges for some cisgender Spanish-speaking respondents due to discomfort, lack of comprehension of transgender identity, and an understanding of nontransgender identity as a "normal" and "self-evident" gender expression. Despite these issues, all Spanish-speaking participants answered the survey questions and gave no indication in the responses during the follow-up probing in the cognitive interview that they were being misclassified.

Comprehension of transgender as including a physical transformation. When asked what they thought "transgender' meant, the majority of English-speaking respondents and a few Spanish-speaking respondents defined "transgender" as a temporary or permanent change and emphasized the physical component of this transformation.

- [R102, English, 83 years] Male, LGBT/Male, Gay: Respondent said transgender is an "umbrella term which covers a wide range of activities...crossdresser...travesti.., a drag queen...to hormones and treatment and surgery."
- [R154, Spanish, 66 years] Female, Not-LGBT/Female, Don't know: When asked "what does transgender mean to you" she said "I imagine that it's somebody who wants to transform into another character."

Comprehension of transgender as a gender identity. Other English- and Spanish-speaking respondents understood transgender as being mostly about one's identity and emphasized issues of one's feelings and "true self" rather than physical transformation, surgery, or medical procedures. The following comments provide examples of responses to a probe as to how respondents would define what it means to be transgender.

- [R148, English, 73 years] Female, Not-LGBT/Female, Straight: "Being born with anatomy that differs from the gender one feels they are."

- [R120, Spanish, 65 years] Female, Not-LGBT/Female, Heterosexual: "people who cannot define themselves as men or women; people who struggle with their identity."

- [R141, Spanish, 71 years] Male, LGBT/Male, Gay: "person who does not feel right in the body that he or she was born."

Inability to define the term "transgender". The majority of Spanish-speaking participants could not provide a definition of transgender or conflated transgender with gay/lesbian or bisexual.

- [R112, Spanish, 88 years] Female, Not-LGBT/Female, Heterosexual: Upon probing about the definition of "transgender" the respondent answered "I have not had much schooling."

- [R127, Spanish, 71 years] Female, Not-LGBT/Female, Don't know: “Transgender, hmmm, I don't know what that word means but it doesn't sound good."

Responses to gender identity questions among Spanish respondents. A number of Spanish-speaking respondents expressed discomfort and/or confusion in the follow-up discussion of the gender identity questions that was not found in the interviews with English speakers. First, several Spanishspeaking cisgender respondents associated their identity with "normal" and one referred to transgender as a "sexual deviation." Others defined their gender identity using terms such as "correct" and "complete," while others thought that their gender identity was "self-evident," indicating that they did not need to report it, there was nothing to discuss, and it was obvious-by looking at them-that they were either male or female. Finally, some respondents were uncomfortable answering and discussing questions about gender identity and wondered why we needed to gather this information.

\section{Discussion}

The results from the cognitive testing of sexual and gender identity questions with older adults add to our understanding of their use in surveys. All of the older adults studied were able to answer both a question about sex assigned at birth and a separate question about current gender identity with no evident inconsistency. Our main concern was whether the proposed two-question approach would be understood 
and work in general population surveys. There was only one transgender participant. Further research is needed to learn more about the responses and any issues that this approach might raise for transgender persons. As gender identity is likely less salient for cisgender than transgender respondents, answering a question about sex assigned at birth and selecting an appropriate gender response option might have been problematic for cisgender respondents. We detected no problems and the two-step gender identity question worked effectively for all of the older adult cisgender English- and Spanish-speaking respondents in our study, even though they may not necessarily understand the term "transgender."

On the contrary, our cognitive testing of the sexual identity question did identify problems among older non-LGBT Spanish speakers, over half of whom did not identify themselves successfully via a response option as "heterosexual, that is not gay (or lesbian)" even though, based on the screener and responses to probing, this option corresponded to their sexual orientation identity. The main source of confusion was their difficulty understanding the term "heterosexual." In addition, the qualitative data elicited in the follow-up probing indicated that for many of the older non-LGBT respondents, sexual identity is not a salient separate aspect of their sense of self. Instead, they viewed it as following intrinsically and naturally from their sex and/or their status as married. As had been described by Miller and Ryan, there were indications that for these majority group respondents, one of their intents in answering the question was to assert their "normality," i.e., to differentiate themselves from sexual minority groups, as not lesbian, gay, or bisexual. ${ }^{11}$ It should be pointed out that the comprehension problems uncovered for older Spanish-speaking adults in response to the sexual identity question overwhelmingly took the form of nonresponse error (i.e., don't know or something else responses) rather than substantive misclassification errors.

This led us to investigate ways to improve the formulation of the Spanish version of the sexual identity question to reduce this type of nonresponse error. Two alternatives were identified. First, to reduce the problems associated with the term "heterosexual," inverting the order of the elements in the response option from "Heterosexual, that is, not gay (or lesbian)" to "Not gay (or lesbian), that is, heterosexual" was suggested. A second alternative was to eliminate the word heterosexual altogether and just retain "Not gay (or lesbian)." To test these alternatives, a new group of 39 Spanish speakers was recruited for cognitive interviews in Spanish. A similar protocol was followed in this round of testing to recruit a diverse group of Spanish speakers, although Medicare eligibility was not a requirement. Twenty of the participants received the first alternative and 19 received the second alternative. Both versions improved the ability of Spanish speakers to select a sexual identity response, especially the first alternative. Only two out of $20(10 \%)$ of the Spanish speakers who received the version of the sexual identity question with the response option "Not gay (or lesbian), that is, heterosexual" said "something else" or "don't know" as opposed to over half of the non-LGBT Spanish speakers in the original round of testing. Among the 19 respondents who were presented with the version without the term "heterosexual," 7 (37\%) said "something else" or "don't know." Thus, while both alternatives were improve- ments on the original Spanish question, the first alternative that retains "heterosexual," but precedes it with the phrase, "not gay (or lesbian)," worked much better.

\section{Conclusions}

Correctly distinguishing the sexual and gender identity of older adults in representative population surveys is essential for research to better understand and address the disparities facing the aging LGBT population. This article presented extensive qualitative testing of one of the most refined measures of sexual identity (the question used in the NHIS) ${ }^{4,11}$ and the recommended practice for assessing gender identity via two questions: a measure of sex assigned at birth and a measure of current gender identity among older adults. ${ }^{8} \mathrm{Cog}$ nitive interviews were conducted with a diverse sample of 57 English and Spanish speakers in the United States. The gender identity questions worked for all groups-LGBT, non-LGBT, English, and Spanish speakers. Although not all cisgender respondents understood the meaning of the term "transgender," they were able to answer both questions successfully. The sexual identity question worked well with lesbian, gay, and bisexual respondents as well as the vast majority of English speakers. Over half of the older adult, non-LGBT Spanish speakers had problems successfully answering the version of the sexual identity question being used in the NHIS, mainly due to confusion and hesitation about the term "heterosexual," which is largely unavoidable in the Spanish version of the question. Follow-up testing of alternative formulations of the question in Spanish was conducted with 39 Spanish speakers. We found that merely reversing the order of the phrases in the heterosexual response category led to a substantial reduction in nonresponse to this question. While this is based on a small sample, we believe this provides a promising alternative to the current standard Spanish version.

In sum, this research contributes further evidence that there are high-quality, well-tested measures of sexual and gender identity that work well for population studies of older adults. This research also contributes to an understanding of what some of the subtle, qualitative issues are that influence the cognitive process of answering these questions. Although no measure in social research is perfect, we believe that the evidence presented here should help researchers overcome reticence and resistance to including measures of sexual and gender identity in research and paves the way to advances in understanding social and health disparities of sexual and gender minorities, including among the older population.

\section{Acknowledgments}

This work was supported, in part, by the Centers for Medicare \& Medicaid Services under Contract Number HHSM-500-2011-00002I Task order HHSM-500-T0012 with NORC at the University of Chicago. We also acknowledge the assistance and input of colleagues at the National Center for Health Statistics' Collaborating Center for Questionnaire Design and Evaluation Research in carrying out the additional Spanish interviews. We greatly appreciate the helpful suggestions and input of the anonymous reviewers, the editorial staff of LGBT Health, and the gracious cooperation of the participants in the cognitive interviews. 


\section{Disclaimer}

The views expressed in this article are those of the authors and do not necessarily represent the views of the Centers for Medicare \& Medicaid Services or the U.S. Department of Health and Human Services.

\section{Author Disclosure Statement}

No competing financial interests exist.

\section{References}

1. Choi SK, Meyer IH: LGBT Aging: A Review of Research Findings, Needs, and Policy Implications. Los Angeles, CA: The Williams Institute, UCLA School of Law, 2016.

2. Fredriksen-Goldsen KI, Kim HJ, Barkan SE, et al.: Health disparities among lesbian, gay, and bisexual older adults: Results from a population-based study. Am J Public Health 2013;103:1802-1809.

3. Wallace SP, Cochran SD, Durazo EM, Ford CL: The health of aging lesbian, gay and bisexual adults in California. Policy Brief UCLA Cent Health Policy Res 2011;PB20112:1-8.

4. Ward BW, Dahlhamer JM, Galinsky AM, Joestl SS: Sexual orientation and health among U.S. adults: National Health Interview Survey, 2013. Natl Health Stat Report 2014; 77:1-10.

5. Gonzales G, Przedworski J, Henning-Smith C: Comparison of health and health risk factors between lesbian, gay, and bisexual adults and heterosexual adults in the United States: Results from the National Health Interview Survey. JAMA Intern Med 2016;176:1344-1351.

6. Hsieh N, Ruther M: Sexual minority health and health risk factors: Intersection effects of gender, race, and sexual identity. Am J Prev Med 2016;50:746-755.

7. Sexual Minority Assessment Research Team (SMART): Best Practices for Asking Questions about Sexual Orienta- tion on Surveys. Los Angeles, CA: The Williams Institute, 2009.

8. The GenIUSS Group: Best Practices for Asking Questions to Identify Transgender and Other Gender Minority Respondents on Population-Based Surveys. Los Angeles, CA: The Williams Institute, UCLA School of Law, 2014.

9. Willis GB (Editor): Cognitive Interviewing. A Tool for Improving Questionnaire Design. Thousand Oaks, CA: SAGE Publications, Inc., 2005.

10. Madans J, Miller K, Maitland A, Willis G (Eds.): Question Evaluation Methods: Contributing to the Science of Data Quality. Hoboken, NJ: John Wiley \& Sons, Inc., 2011.

11. Miller KS, Ryan JM: Design, Development and Testing of the NHIS Sexual Identity Question. Atlanta, GA: Questionnaire Design Research Laboratory. Office of Research and Methodology, National Center for Health Statistics, 2011.

12. Dahlhamer JM, Galinsky AM, Joestl SS, Ward BW: Sexual orientation in the 2013 National Health Interview Survey: A quality assessment. Vital Health Stat 2 2014;169:1-32.

13. Stern MJ, Michaels S, Milesi C, et al.: Medicare Current Beneficiary Survey (MCBS) Task 1.32.a: Develop and Test Sexual and Gender Minority Status (LGBT) Items: Final Summary Report. 2016. HHSM-500-2014-00035I, Task Order \# HHSM-500-T0002.

14. Jans M, Viana J, Grant D, et al.: Trends in sexual orientation missing data over a decade of the California Health Interview Survey. Am J Pubic Health 2015;105:e43-e50.

Address correspondence to: Stuart Michaels, PhD Academic Research Centers NORC at the University of Chicago 1155 E. 60th Street Chicago, IL 60637

E-mail: michaels-stuart@norc.org 